\title{
Integrated modelling of the ecosystem of the Niger river inland delta in Mali
}

\author{
M. Kuper ${ }^{\mathrm{a}, *}$, C. Mullon ${ }^{\mathrm{b}}$, Y. Poncet $^{\mathrm{c}}$, E. Benga $^{\mathrm{d}}$ \\ ${ }^{a}$ CIRAD-TERA, 73 rue J.-F. Breton, 34398 Montpellier, France \\ ${ }^{\mathrm{b}}$ Department of Oceanography, Institut de Recherches pour le Développement (IRD)-GEODES, \\ University of Capetown, 7700 Rondebosch, South Africa \\ c IRD-Centre d'Orléans, 5 rue du Carbone, 45072 Orléans, France \\ ${ }^{\mathrm{d}}$ Ecole Supérieure Polytechnique, Université Cheikh Anta Diop, Dakar, Senegal
}

Received 20 February 2002; received in revised form 1 October 2002; accepted 13 December 2002

\begin{abstract}
The Niger River inland delta in Mali constitutes a vast $36,000 \mathrm{~km}^{2}$ area of wetlands, producing numerous natural resources, exploited by fishermen, pastoralists and farmers. It is also a humid zone protected through the Ramsar convention of 1971. To promote the management of its natural resources, an integrated model has been developed in order to simulate the evolution of this ecosystem in relation to different scenarios of population increase, diminishing natural flooding (climatic droughts, construction of dams), increasing stress on land tenure and access to farming areas, technological advances, current administrative decentralisation policy. Possible applications of the model are illustrated through an analysis of the impact of the construction of dams on the traditional farming systems of the delta (fishing, rice cropping, pastoralism), and through a sensitivity analysis of an evolution in the fishing techniques on the revenues of fishermen. The validity of the results of the modelling is discussed and its use for other studies in the field of integrated natural resources management analysed.
\end{abstract}

(C) 2003 Elsevier Science B.V. All rights reserved.

Keywords: Integrated modelling; Ecosystem; Management; Natural resources; Hydrology; Hydrobiology; Fisheries

\section{Introduction}

\subsection{Towards the integrated management of an exploited ecosystem}

The Niger River inland delta in Mali is one of the larger wetlands in Africa (Fig. 1). It covers an area

\footnotetext{
* Corresponding author. Tel.: +33-467-615-639; fax: +33-467-614-415.

E-mail addresses: kuper@cirad.fr (M. Kuper), cmullon@physci.uct.ac.za (C. Mullon), poncet@orleans.ird.fr (Y. Poncet), benga@esp.sn (E. Benga).
}

of about $36,000 \mathrm{~km}^{2}$, and produces one-tenth of the country's rural gross domestic product. Every year, an area of about $10,000-20,000 \mathrm{~km}^{2}$ is inundated. The extent of the inundated area has been even bigger before the Sahelian droughts of the 1980s. The regeneration of natural resources depends directly on the extension of the flooding. One million people inhabit the delta, a tenth of the country's population according to the 1998 census. The delta is frequented by about 2 million cattle, and as many sheep and goats according to 1991 figures of the Malian Ministry for Rural Development. Farmers cultivate an area ranging from 50,000 to 130,000 ha of deep-water rice with 


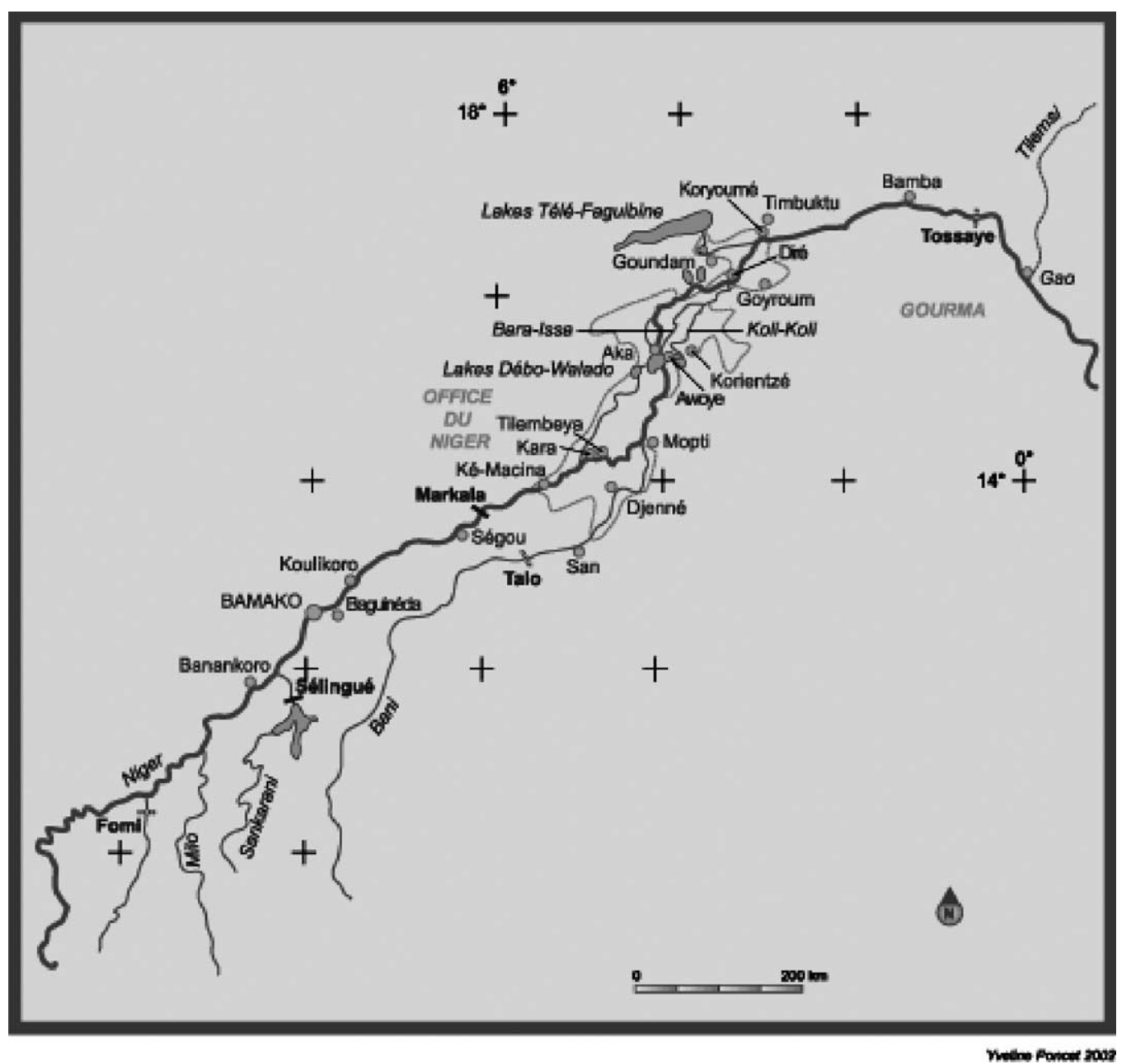

Fig. 1. Location map of the inland delta of the Niger river in Mali.

yields generally below 1 ton/ha. The annual fisheries production is over a 100,000 tons during wet years (Breuil and Quensière, 1995).

The ecosystem of the delta is resilient and used to large inter-annual fluctuations in the availability of water resources. Its natural resources have adapted to these fluctuations. After the abundant floods of 1994, for example, the annual fish production tripled. An estimated 100,000 tonnes of fish were captured in the delta, three times the amount of fish captured in 1993, despite the droughts in the 1970s and 1980s. The traditional production systems in this ecosystem take this variability into account and peasants have different strategies to cope. Firstly, they have a great mobility and make use of the resources wherever they are available in this ecosystem. Secondly, families have more than one professional activity, which allows them to select those activities in a given year that are likely to procure them sufficient revenues or food.

Since 1973, the Sahel has been confronted with a decline in rainfall and diminishing water resources (Fig. 2). The hydraulicity (ratio of the average discharge of a given year and the average discharge over the entire reference period) of the Niger river has declined to a much larger extent than the rainfall index over the same period. Even when there is sufficient rainfall, the water availability of the Niger river is not up to the same level as it used to be before these 


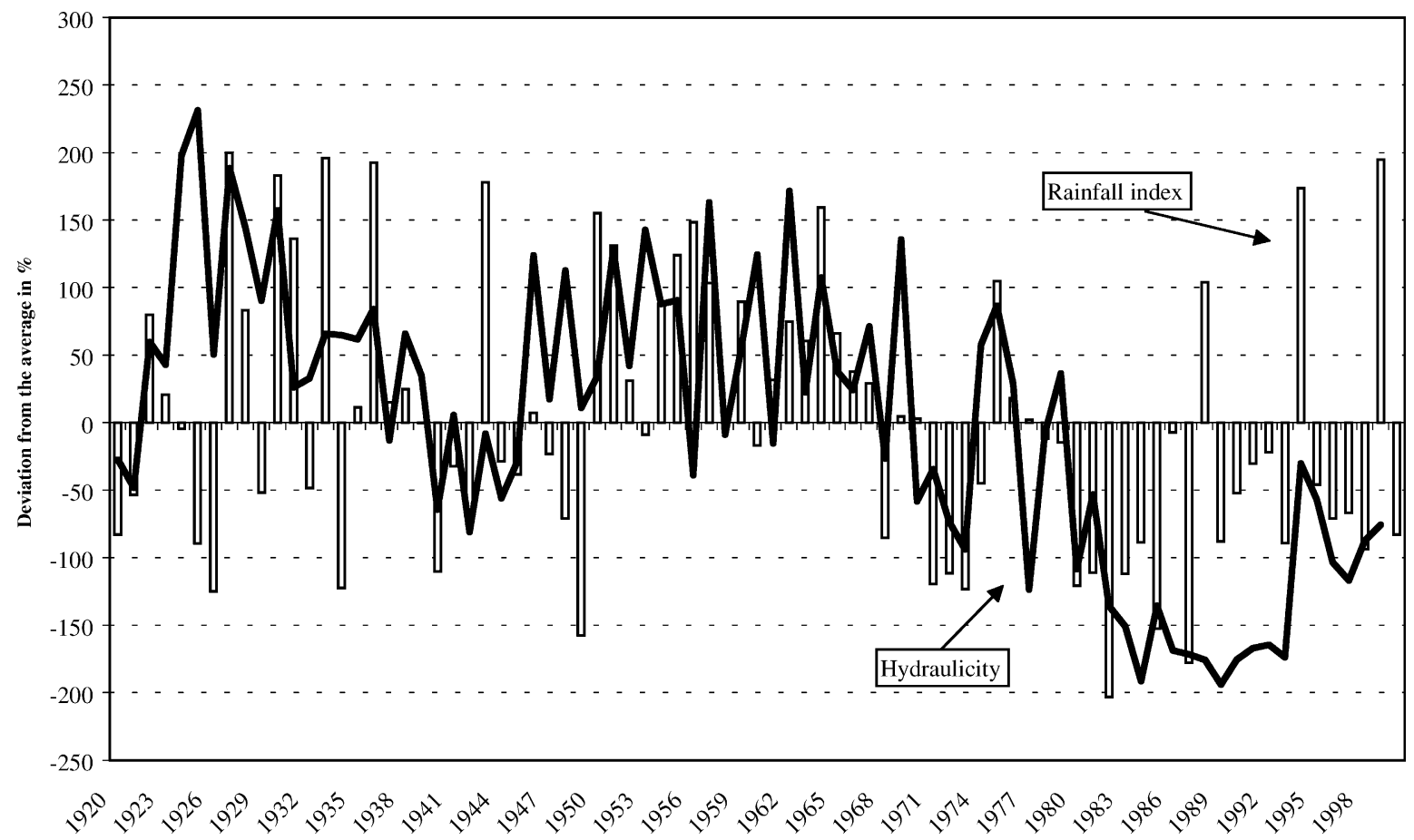

Fig. 2. A historical comparison of the rainfall index in Ségou and the hydraulicity of the Niger river at Koulikoro (Mali).

droughts. This non-linear relationship is attributed by hydrologists to the depletion of groundwater reserves in the upper catchment areas (Olivry, 1995; Mahé et al., in press).

In wetlands like the Niger River inland delta in Mali, the hydrological regime, the dynamics of the natural resources and the human activities (fisheries, agriculture, livestock) are closely associated. The shortfall in the availability of water resources has, therefore, a direct impact on the amount of natural resources regenerated in this ecosystem. In addition, these wetlands have offered refuge to large numbers of people, confronted with droughts in areas surrounding the Niger river delta. This has led to increasing pressure on the existing natural resources and competition over the access to these resources.

Several developments threaten the functioning of the Niger river inland delta. Just upstream of the delta a large-scale 67,000 ha irrigation scheme, operated by the Office du Niger, diverts annually about $10 \%$ of the Niger supplies (Hassane et al., 2000). Currently, there are a number of projects underway to extend the irri- gated area by about 13,700 ha in the coming years. In addition, the master plan of the scheme envisages ultimately an irrigation infrastructure for over 250,000 ha. The governments of Guinea and Mali are also planning the construction of a number of dams on the upstream catchment areas for the generation of hydropower or the development of irrigation schemes. The ecosystem of the Niger River inland delta as well as the traditional farming systems that exploit its natural resources in the flood plains and the lakes (fisheries, agriculture, livestock) depend directly on the extent of the annual river floods (Poncet and Orange, 1999). Any extension of the irrigation schemes upstream of the delta or the installation of dams is, therefore, going to have an impact on the ecosystem and thus on the traditional farming systems. At the same time, the different farming systems are changing in nature under the influence of new technologies (fishing gear, motorization of boats, introduction of animal traction....).

The sustainability of the exploitation of the natural resources of the delta is crucial to both its economic development as well as for the conservation of 
its unique ecosystem. A research programme was carried out in order to understand the dynamics of the regeneration of the natural resources, to evaluate their (traditional) exploitation, and to assess the sustainability of these farming systems. One of its aims was to contribute to the acceptance of the delta as a management unit, while anticipating its future evolution. The questions being:

- How will this ecosystem be transformed under population pressure, increasing stress on land tenure and access to farming areas, technological advances, impact of hydraulic works (dams), the current administrative decentralisation policy?

- How to quantify the relationships between the availability of water and the performance of the different farming systems, including the needs for conserving this unique ecosystem, identified in the RAMSAR Convention, in order to take better decisions on water resources development (Gleick, 2000; Simonovic, 2000).

Two aspects needed to be taken into account: (1) the long-term dynamics of the physical, biological and human systems, (2) the needs and the multiple uses of the populations concerned.

\subsection{Integrated modelling}

Modelling is used here to provide a platform to combine the analysis of the dynamics of the natural resources and the understanding of human activities, while representing the spatial interactions and structuring them in a temporal framework. The objectives of the modelling were the description of the system, the analysis of its functioning, and the simulation of its evolution.

Integrated modelling of an exploited ecosystem, has to consider the diversity of the processes to be represented, the different scales and levels of organisation they imply. Capitalising on the results of existing thematic models or even interfacing them, to build a representation of complex systems is a possible research option, but this "may be fraught with danger" (Gaunt et al., 1997). The compatibility of the different spatial and temporal scales used in the sub-models, their different levels of complexity (deterministic models, stochastic models, etc.) make the compounding of sub-models relatively compli- cated with subsequent multiplication of errors. In this study, an integrated model was, therefore, developed on the basis of a representation of the entire ecosystem.

The specifics of this modelling experience lies in:

- the extensive existing knowledge of the ecosystem (Gallais, 1967; Brunet-Moret et al., 1986; Quensière, 1994; Olivry, 1995);

- the magnitude of the area considered, i.e. the entire delta $\left(36,000 \mathrm{~km}^{2}\right)$;

- the management focus;

- the structure of the model, based on the overlapping of different layers corresponding with existing organisation levels.

It constitutes a relevant case study to contribute to the development of a generic methodology for integrated modelling of complex systems (Lee and Dinar, 1995; Grant and Thompson, 1997).

\subsection{Methodology}

A five-step approach is proposed (Kuper, 1997; Strosser, 1997; Gaunt et al., 1997):

1. Identify the different mechanisms in interaction in the considered ecosystem;

2. Identify the spatial and temporal relationships, inter and intra, e.g. Blöschl and Sivapalan, 1995;

3. Select mechanisms for representing each process;

4. Test the numerical robustness of the aggregation of the representation of the different processes;

5. Carry out the calibration, validation and robustness tests.

Involved jointly in these five steps of constructing the integrated model, modellers, researchers, decision makers and other actors, needed to share information while advancing in the research process. Prototypes of the model were discussed and criticised by the different actors in different formal and informal sessions. The structure of the model has been conceived to integrate the knowledge and research results from different disciplines: hydrology, hydrobiology, geography, agronomy, and information sciences. The integrated modelling played thus a central role in the development of the research programme. It stimulated the different scientific disciplines, from the natural sciences to the social sciences (Axelrod, 1997). 


\section{The structure of the model and the computer software}

\subsection{Multi-layer structure}

When defining the software implementation, it was attempted to respect the modular configuration of the model based on the definition of thematic modules, each representing a different process. This has resulted in a multi-layer architecture (Fig. 3) allowing a spatial and dynamic representation for each process, which constitutes one of the major research challenges in water resources management (Schulz, 2000).

This configuration allows an independent development and improvement of thematic modules and it allows thematic output that can be verified and analysed. Object oriented programming principles have proved to be very practical for the implementation of a multi-layer system.

\subsection{Interface}

Through the user interface the main features of the model are represented: a spatial structure with maps, a dynamic construction with graphic anima- tions of the different entities, and a functional structure by allowing direct manipulation of the control parameters.

The user can fix the value of the control parameters, and then visualise its impact on the functioning of the ecosystem through a simulation. The model can perform a detailed comparison of the results of scenarios based on two different values of a given control parameter. It can perform a sensitivity analysis giving a global description of the dynamics based on 10 different values given to a control parameter. It can produce thematic maps of the simulation results, thematic animations of the simulation results, graphs depicting the comparison between two different scenarios, and graphs depicting the results of sensitivity analyses.

\subsection{Utilisation}

The model is accessible via Internet: http://www. orleans.ird.fr/MIDIN/. The model can be executed in any Java compatible environment, version Java 1.2, either through Internet via a Navigator software, or through an autonomous application on PC. The user's manual and the technical documentation are available at the same site.

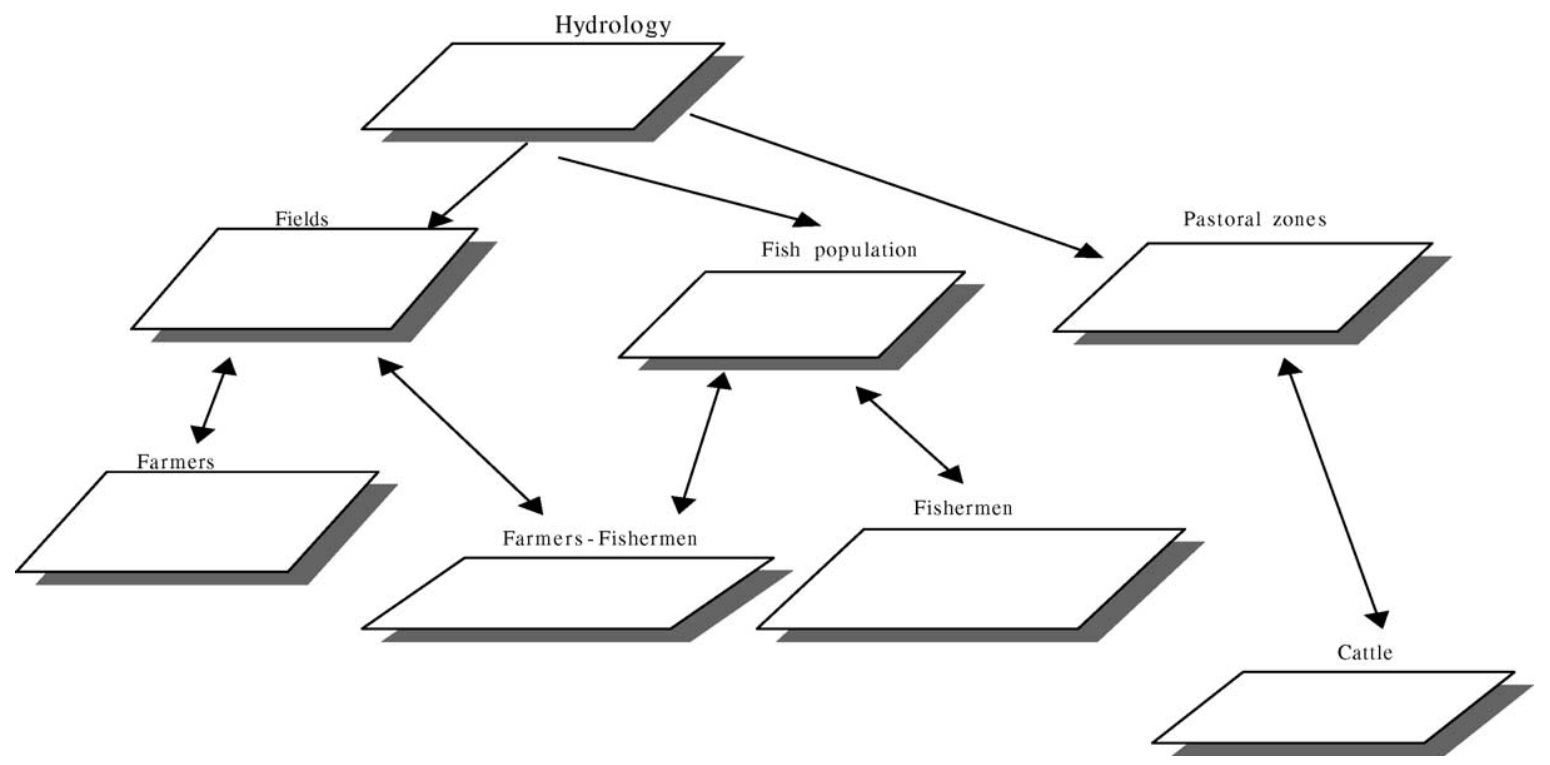

Fig. 3. Multi-layer structure of the model. 


\section{Scales, entities and mechanisms}

\subsection{Scales and entities}

A common extension and spatial scale for all processes has been selected, and the dynamics of the system, as well as the evolution of representative spatial entities, have been represented in this framework. The spatial extension of the model is the maximum inundated area of the delta from Ké-Macina and San to Timbuktu (Fig. 1).

The model runs during 3 hydrological years, from May to April: 1993/1994, 1994/1995 and 1995/1996. The choice of selecting three hydrological years in the recent past was guided by the fact that the different stakeholders associated a number of very characteristic events to these different years (the floods of 1994/1995, the devaluation of the West-African franc in 1994, etc.) and were found to be more interested in discussing the results of the modelling approach. These years represent a dry, wet and average year in terms of rainfall and extension of the inundated area for the period 1970 to date. It was decided to use the period 1970-2000 as the reference period for the modelling, since the hydrological functioning of the delta has changed since the Sahelian droughts in the 1970s and 1980s (Mahé et al., in press). The time step used by the model is a 15-day period.

The entities represented are the hydrological units (flood plains, lakes and rivers), groups of fishermen, groups of farmers, herds of bovines, and the production zones of the different farming systems (fisheries, agriculture and herding). Three types of hydrological entities have been defined (Kuper et al., 2002): (1) rivers and channels conveying water, schematised by straight lines ("segments"), (2) connections, contact points where rivers and channels diverge or converge and (3) flood plains and lakes, where water is stored temporarily or permanently, schematised by circles. The hydrosystem is thus represented by segments (rivers, channels), cones (plains, lakes) and knots (confluence, defluence). There are 109 entities: 7 lakes, 12 flood plains, and 90 segments (Fig. 4). The availability of water intervenes in all the different processes and in all entities, which makes it the main explicative variable of the model.

The following spatial entities have been identified: farming zones, fishery zones and pastoral zones. All

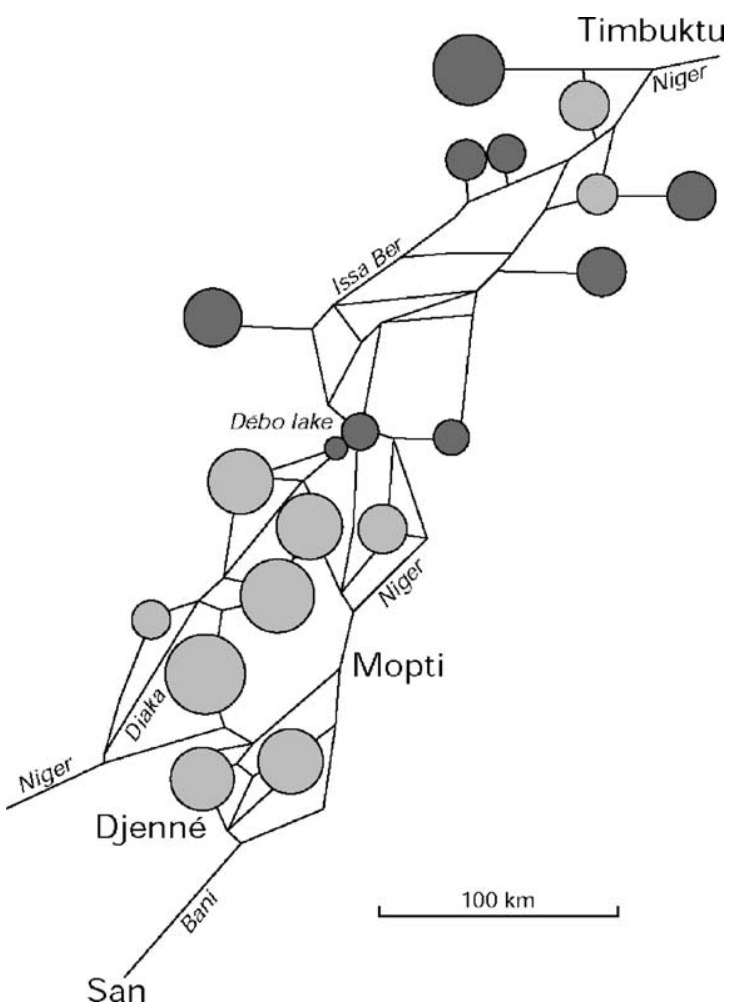

Fig. 4. Hydrological entities: lakes and flood plains, rivers and channels, confluence and defluence.

zones are linked to an hydrological entity. The other entities represented in the model are groups of peasants (fishermen, farmers), and herds of cattle, which are linked to their zone of origin, but who have also access to other zones (principle of mobility). The access to the different zones is subject to traditional rights and regulations (cf. Gallais, 1967; CIPEA-ODEM, 1983; Baumann et al., 1994) through family ties (principle of connectivity). Cattle herds are considered as acting entities in the process of production, just like rice farmers and fishermen.

\subsection{A spatial approach, a behavioural model}

A geographical approach is used to understand and to represent the processes of regeneration of natural resources and the exploitation of its resources. The selected entities have a precise geographical sense, since they have been geo-referenced. They have a hydrological sense, since they convey and store water. They 
have a socio-economic sense, since they correspond to the different exploitation sectors of the farming systems of these wetlands. The inland delta as a natural system has been limited geographically by its outer perimeter of fluvial inundation, but has been functionally defined as an oriented and open network.

The spatial behaviour of groups of individuals considered homogeneous is represented, as documented in the different research papers on the delta (Gallais, 1967; CIPEA-ODEM, 1983; Laë and Morand, 1994; Baumann et al., 1994; Poncet et al., 2001). The model represents groups of peasants, residing in a village with a specific behaviour in terms of exploitation and migration. Behaviour is not based on "rational choices", e.g. game theory, (Axelrod, 1997), but on social rules and patterns. The hypothesis is that the spatial behaviour of agents is strongly structured and that in the short term, this structure does not change, and can thus be quantified and used as a basis for extrapolation. This is one of the reasons for adopting a maximum timeframe of 3 years for the simulations. Beyond that, changes in external environment would lead to modification of social patterns and behaviour.

\subsection{The hydrological module: a reservoir model}

The 15-day average water levels have been determined for all hydrological objects for every time step on the basis of daily observations during the years 1993-1996. For each time step, the water level enables the calculation of the inundated area for each object. Since cones represent the flood plains and the lakes, it suffices to calculate the radius at time $t$, which is a function of the water level and the geometry of the object (bed level, maximum water depth, minimum and maximum radius). The minimum and maximum radii determine the extent of the inundation (Fig. 5).

$R(t)=s+(l-s) \frac{w(t)}{d}$

where $R(t)$ is the radius of the flood plain or lake $(\mathrm{km})$ at time $t, l$ the radius of the flood plain or lake at maximum flood $(\mathrm{km}), s$ the radius of the flood plain or lake during low flow, $d$ the depth of the flood plain or lake, and $w(t)$ the water level.

The inundated area at time $t$ is then calculated based on the radius during the same time step $\left(\pi r^{2}\right)$. The inundated area of the segments (channels, rivers) is calculated by multiplying the length of the segment (fixed) with the width, which varies between the high water and mean water bed.

For each of the 109 hydrological entities, the hydrographic characteristics were determined: radius at low water, radius at maximum flood level, maximum water height. Secondly, daily water levels for the period 1993-1996 have been determined using the observations of the National Hydraulic Agency of 18 hydrological stations. These data have been analysed using the HYDROM database and interpolated for the different hydrological entities (Brunet-Moret et al., 1986; Boyer and Cochonneau, 1994, Marieu et al., 1998).

The model allows the simulation of the impact of river works on the river discharges, the extent of the flooding, and on the farming systems. This concerns two different development schemes:

1. The construction of a dam upstream of the delta. The Sélingué dam in Mali, commissioned in 1981, is the only hydraulic structure capable of regulating the river flow of the Niger River. This dam, with a storage capacity of 2.17 billion $\mathrm{m}^{3}$, maintains

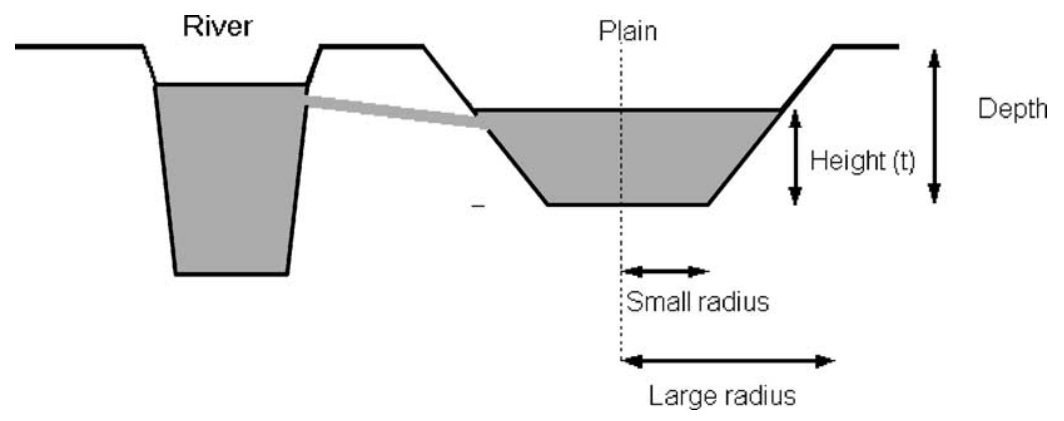

Fig. 5. The water level allows to determine the inundated area of the hydrological entities. 
the river flow at a minimum of $100 \mathrm{~m}^{3} / \mathrm{s}$ during the dry season at the hydrological reference station of Koulikoro (Hassane et al., 2000). A formula that represents the croping of the flood by this dam has been developed (see Appendix A). In addition, different dams have been projected upstream of the delta in Fomi (Guinea) and Talo (Mali), cf. Fig. 1. Their impact can also be simulated in the model.

2. The construction of a dam downstream of the delta. The projected dam of Tossaye (Fig. 1) has been conceived for the generation of hydropower, the development of navigation and the agricultural development of the area concerned. In this study, only its impact on the Niger river inland delta is analysed. As opposed to the upstream dam, the storage capacity is only indirectly of interest here. It is the backwater effect, caused by the water level of the reservoir, which will provoke an increase of water levels in the delta. A formula that accounts for this effect is developed in Appendix B.

Three control parameters are available in the hydrological module. Firstly, the flood level: this parameter allows to weigh the values of the actual water levels observed in 1993/1994, 1994/1995 and 1995/1996 (in $\%)$. This parameter is used to envisage the effect of several successive bad hydrological years and allows to make abstraction of the actual hydrological events of these 3 years. Secondly, the dam upstream: this parameter allows to simulate the impact of a dam upstream of the delta on the 2-weekly water levels for all hydrological objects. Thirdly, the dam downstream: this parameter allows to simulate the impact of a dam downstream of the delta on the 2-weekly water levels for all hydrological objects.

\subsection{The hydrobiological module}

This module is based on Bousquet et al. (1993) and represents the temporal and spatial dynamics of the generation and spreading of fish populations. The reproduction of fish takes place in the flood plains. When the fish is in these plains, its abundance follows a logistic evolution in which the carrying capacity $K$ depends on the inundated area:

$A_{i}(t+1)=A_{i}(t)+r A_{i}(t)\left(1-\frac{A_{i}(t)}{K_{i}(t)}\right)$ where $A_{i}$ is abundance, $K_{i}$ the carrying capacity which explicitly depends on the surface of the flooded area, $r$ the natural growth level of the fish population.

The diffusion of fish takes place in all entities (segments, plains, lakes), following an equation of mixing, depending on the connectivity of the system between two entities $i$ and $j$ :

$A_{i}(t+1)=A_{i}(t)+\sum_{j} B_{i j} \frac{A_{j}(t) S_{i}(t)-A_{i}(t) S_{j}(t)}{S_{i}(t)+S_{j}(t)}$

where $B_{i j}$ is the connectivity $\left(B_{i j}=B_{j i}\right.$ ), $A_{i}$ the abundance and $S_{i}$ the area of the hydrological entities.

A fertility parameter $r$ represents the natural growth level of the fish population. It is used to simulate the introduction of fish species that are more or less prolific than those species already present. A diffusion parameter is used to quantify the speed of diffusion of the fish populations. It represents the speed of homogenisation of the fish concentrations between two adjacent hydrological entities (Bousquet et al., 1993).

\subsection{The fishing and agricultural activities module: a "pulling" model}

The farming systems are represented through a "labour market" model, distinguishing between the fishing and agricultural activities, represented through a "pulling" model, and livestock activities, represented through a "pushing" model.

The inhabitants of the delta are represented by groups of fishermen, farmers and fishing farmers who take part both in fishing and farming activities. All groups can move to production zones whenever there are opportunities to exploit the natural resources. Moving to a production zone is possible when a particular group has traditional links with the zone (cf. Fig. 6). Whether or not a group will move will depend on the availability of natural resources and thus on the inundation of the area.

A group of farmers or fishermen are generally linked to several farming or fishing zones. For example, the fishermen of the southern part of the delta (Diaka, Mopti) leave their settlement zones during the low water season to move towards the central lakes (Débo, Walado). This mobility applies equally to farmers. The farmers of zones deficient in cereals (region of 

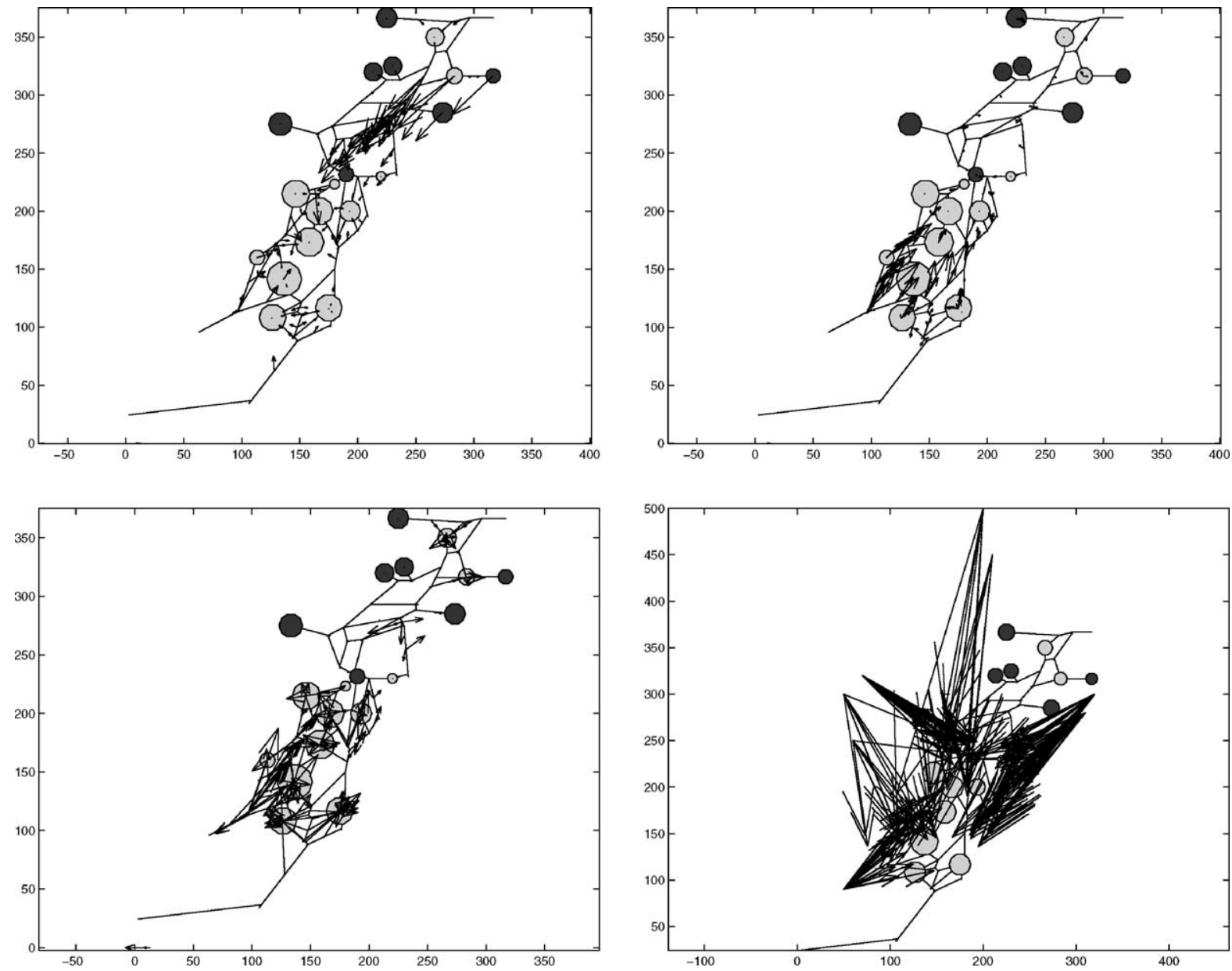

Fig. 6. Connections between groups of farmers and fishermen, and farming zones in the inner delta of the Niger river. Left column, top: links between farmers and farming zones. Left column bottom: links between agro-fishermen and farming zones. Right column, top: links between fishermen and fishing zones. Right column, bottom: links between cow herds and pastoral zones.

Timbuktu), for example, move during the crop season towards the large production plains in the south, upstream of the central lakes, to cultivate deepwater rice.

A migration behaviour parameter allows to put restrictions on the migration of the different groups, representing the maximum distance a particular group can cover between its settlement area and the production zones. A capitalistic attitude parameter allows to distinguish between the situation in which farmers are engaged in subsistence agriculture with a negative relationship between the propensity to work and the capital accumulated, and the situation in which farmers have an investment attitude, implying a positive relationship.
In the fisheries module, the actors are groups of fishermen or fishing farmers, and the resource is the fish (cf. hydrobiological module). The following mechanisms are represented:

1. Calculation of the labour requirements for the different fishing zones: these requirements depend on the fishing season and the fishing capacity of each zone. The hydrological year is divided in six periods: (1) low water level and dry season, (2) low water level and rainy season, (3) rising water season, (4) flood season, (5) falling water season and cool season, (6) falling water and hot season. The fishing capacity for each season and each fishing zone 
equals the maximum number of fishermen that can be supported in a given fishing zone.

2. Calculation of the availability of labour: the availability is calculated on the basis of the subsistence needs of fishermen and the capitalistic attitude of individual groups.

3. Allocation of fishermen to the fishing zones: the allocation of fishermen is targeted to meet the labour requirements of the different zones, while taking into account the availability of labour. In case of a surplus, the labour from other zones goes home. In case of repatriation of labour, the labour that is closest to their settlement zone goes home first, while taking into account the sedentary level of groups. Professional migrant fishermen are thus distinguished from sedentary fishermen, who fish occasionally in other areas and who will go home before the migrant fishermen. The equilibrium between supply and demand is reached in five consecutive time steps.

4. Fishing activities: the fish catches in each fishing zone depend on the catchability (Beverton and Holt, 1957).

$y(t)=q A_{i}(t) e$

where $y(t)$ represents the catches, $q$ the catchability, $A_{i}$ the abundance and $e$ the fishing effort. The number of fishing trips represents the fishing effort. The catches are multiplied by the price in order to obtain the revenues of fishermen.

The fishing capacity for the different zones has been determined through surveys and interviews (Quensière, 1994). For each group of fishermen, the size of the group (number of families) as well as their traditional rights to the different fishing zones are known (ibid).

A catchability parameter represents the proportion of biomass present that will be captured during each fishing trip or unit of fishing effort. It varies for each season and for each zone. It is higher, for example, during the low water seasons when the fish is better accessible to fishermen. In the model, the coefficient can vary from 40 to $400 \mathrm{~kg}$, while the default value is 40 . An increase in the catchability over time can signify a modernisation in the fishing techniques (boats, nets). The price parameter in the model is the price for fresh fish. It can vary from 100 to 1000 francs CFA, while the default value is 500 francs CFA. ${ }^{1}$

The actors of the agricultural module are the farmers and the agro-fishermen. The agro-fishermen are linked to fishing zones as well as to farming zones. Their choice of activity depends on the abundance of fish and the opportunities of cultivation (fertility, area inundated) in the zones to which they have access. Because of their history and traditions, the agro-fishermen have a preference for fishing.

In terms of crops only the deepwater rice (flood farming, recession farming), is taken into account in the model, since this is the traditional staple crop of the area on which the local diets are based (Viguier, 1937; McIntire, 1981). The farmers move to the different farming zones depending on the availability of seeds, the inundated areas, and their access rights.

The following mechanisms are represented:

1. Calculation of the labour requirements for the different farming zones: the labour requirements for a given time step are based on the agricultural activities: (1) land preparation, (2) upkeep (weeding, treatment), (3) harvest and threshing. The calendar of activities and the work load are based on Gallais (1967) and Kuper et al. (2002).

2. Calculation of the availability of labour: on the basis of the subsistence needs of farmers and the capitalistic attitude of individual groups.

3. Allocation of farmers to the farming zones: the allocation is targeted to meet the labour requirements of the different zones, while taking into account the availability of labour. The equilibrium between supply and demand is reached in five consecutive time steps.

4. Farming activities: the area of rice sown in a particular farming zone depends on the maximum farming area, the labour available and the availability of seeds.

$A s_{i}=\frac{A s_{i}^{\max } \times s \times L a_{i}}{L r_{i}}$

where As is the area sown, $s$ the index of availability of seeds, $L a$ the number of farmers working in zone $i, L r$ the labour requirements in zone $i$. The area sown does not depend on the extent of floods,

\footnotetext{
${ }^{1}$ One hundred francs CFA is worth 0.15 euros.
} 
since farmers do not have precise information on the expected flood levels, although they have their own traditional indicators.

5. The area of rice that is maintained (weeding, treatment) depends on the area that is sown, the area inundated (and thus the importance of the floods and the morphology of the plains), and the availability of labour:

$A m_{i}=\frac{A s_{i} \times A i \times L a_{i}}{A s_{i}^{\max } \times L r_{i}}$

6. The rice production depends on the area maintained, the availability of labour, and the yield, which is subject to a number of constraints during the season, and which is controlled by a productivity index:

$P_{i}=\frac{A m_{i} \times p \times L a_{i}}{L r_{i}}$

where $P_{i}$ is the rice production in zone $i$, and $p$ is a productivity index or yield.

In each farming entity, the arable area is known, using the annual report of the Malian Ministry for Rural Development. For each group of farmers, the size as well as the access to the different farming zones is known (Kuper et al., 2002).

The productivity parameter represents the crop yield and can vary between 200 and $2000 \mathrm{~kg} / \mathrm{ha}$, while the default value is $900 \mathrm{~kg} / \mathrm{ha}$. The price parameter, which is the price of paddy per $\mathrm{kg}$, can vary between 50 and 200 francs CFA and is fixed at 100 francs CFA by default. There is a parameter for the availability of seeds; it varies between 0 and $100 \%$ and is fixed at $100 \%$ by default, i.e. all necessary seeds are available.

\subsection{The pastoral activities module: \\ a "pushing" model}

Herds of cattle move in the delta following traditional tracks and penetrate in pastoral zones on the basis of traditional access rights (cf. Gallais, 1967; CIPEA-ODEM, 1983). The cattle herds go from one zone to another based on the season, and based on the grazing capacity: the zones "push out" the herds when they are saturated.

In this module the resource is the pasture and the actors the transhumant cattle herds. These herds enter the south of the delta when the water levels start to fall (November-December) and leave the delta during the rainy season when pasture is abundant in the dry areas north of the delta and the flood plains of the delta start to be inundated. The cattle herds are, therefore, absent from the delta from July to November.

The herds move inside the delta depending on the availability of pasture (carrying capacity) and the traditional rights of the owners of the respective herds on pasture and land. Two types of herds are further distinguished: "natives" and "foreigners". The first ones have traditional rights to a particular pasture area, the latter ones have to pay a tribute to the landowners. In case of a lack of pasture, the native herds move first into a new pastoral zone. The foreign herds follow. The lack of pasture has an impact on the health condition of the herds, which increases the mortality and obliges the herdsmen to sell animals.

The following mechanisms are represented:

1. Calculation of the carrying capacity for each pastoral zone: this is the maximum number of cattle that the different zones can accommodate, calculated at every time step. The carrying capacity depends on the pasture available. The pasture develops on the exondated and on the inundated areas. Three qualities of pasture are identified for the inundated areas (CIPEA-ODEM, 1983; Breman and de Ridder, 1991), according to vegetation types: (1) vetiverae, (2) oryzae, (3) bourgou (Echinochloa stagnina, Vossia cuspidata) (cf. Fig. 7). The development of each type of pasture depends on the maximum water level attained for a given year, hence the notion of sills. If, for example, the maximum water level attains the sill "oryzae", the development of bourgou and of the oryzae is assured. The carrying capacity is not the same for the different vegetation types: bourgou has a capacity almost five times higher than the vegetation of the exondated area (CIPEA-ODEM, 1983; Breman and de Ridder, 1991).

2. Allocation of herds to the different pastoral zones: a reallocation is carried out whenever the state of the pasture changes according to the season or the pressure of the cattle in previous time steps. The cattle herds move whenever the carrying capacity of a zone is inferior to the number of cattle present. 


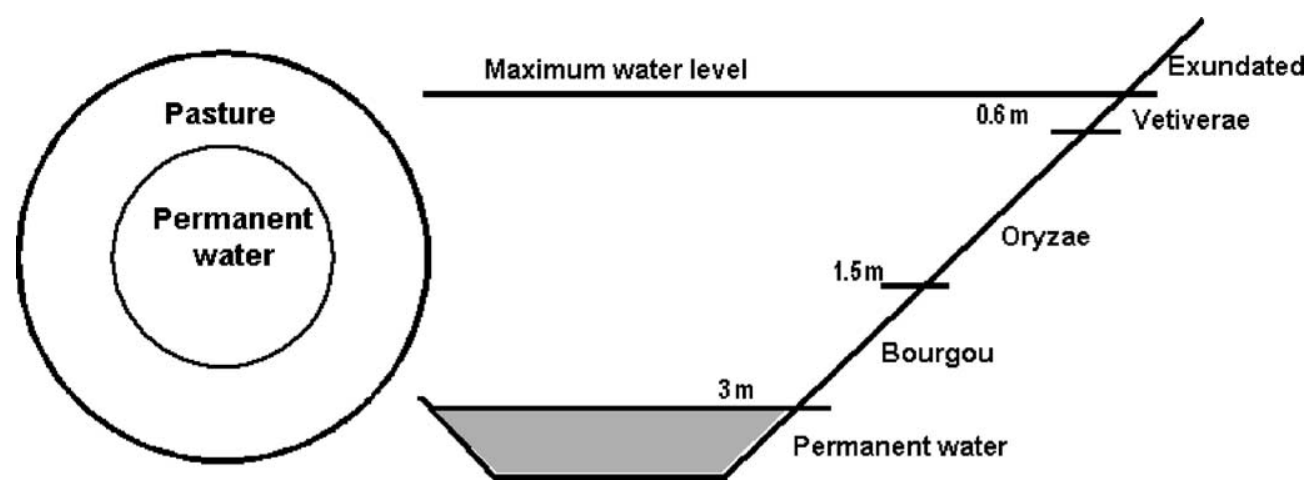

Fig. 7. Pasture sills in a flood plain, depending on the maximum seasonal water.

For each herd present in such a zone, the zone of destination is selected from those zones that can accommodate the most cattle (difference between carrying capacity and cattle present).

3. Calculation of the demography of the herds: the demography is updated in the different zones based on the natural growth rate of the herds and the health status of the herds, which in turn depends on the quality of the pasture. If the carrying capacity is superior to the number of cattle present in a zone, the health status of the herds increases by $40 \%$. If it is inferior, the health status diminishes by $30 \%$. In this case a proportion of the herd is sold $(1 \%)$ to ensure proper feed for the rest of the herd.

There are 60 pastoral zones and 14 different cattle herds with a total number of about 1.7 million cattle in the delta. For each zone, the repartition of the different vegetation types (as a ratio of the total maximum inundated area) has been determined (CIPEA-ODEM, 1983; Breman and de Ridder, 1991).

The bourgou parameter represents human interventions in the vegetation in the delta, for example the replanting of bourgou or the replacement of bourgou by rice. This parameter varies between 0.2 and 0.4 with a default setting of 0.2 , which is a ratio of the total inundated area covered by bourgou. The health status parameter reflects the impact of degrading feeding conditions on the health status of a given herd. This in turn will prompt cattle owners to sell a proportion of their herd. A sales attitude parameter represents the number of cattle (in \%) sold in case of a degradation in the health status of a given herd.

\section{Simulation results}

\subsection{Impact of a dam upstream}

The impact of the construction of a dam upstream of the delta in addition to the existing Sélingué dam and its impact on the water levels in the delta and on the different production systems (fishing, cropping and pastoralism) was simulated for all entities. In Fig. 8, the results of the simulation are illustrated for the river Koli Koli and its floodplains in the north of the delta (Fig. 1), assuming that the dam has a reservoir capacity of 10 billion $\mathrm{m}^{3}$.

The construction of the dam leads to a storage of water during the flood season (July-December) and water releases during the dry season (January-June). The main impact is a flattening of the flood crest and a decrease of the inundated area in the flood plains and river reaches. The traditional rice cultivation is directly hit, showing a decrease in the cultivated area, a decrease in the number of families cultivating rice and a decrease in the farm revenues. The attenuation of the floods and a sustaining of the dry season supplies increase the length of the fishing season, but decrease the revenues of fishermen (Fig. 8).

\subsection{Impact of a dam downstream}

The impact of the construction of a dam immediately downstream of the delta (e.g. the Tossaye dam) on the water levels in the delta and on the different production systems was simulated. Assuming a 


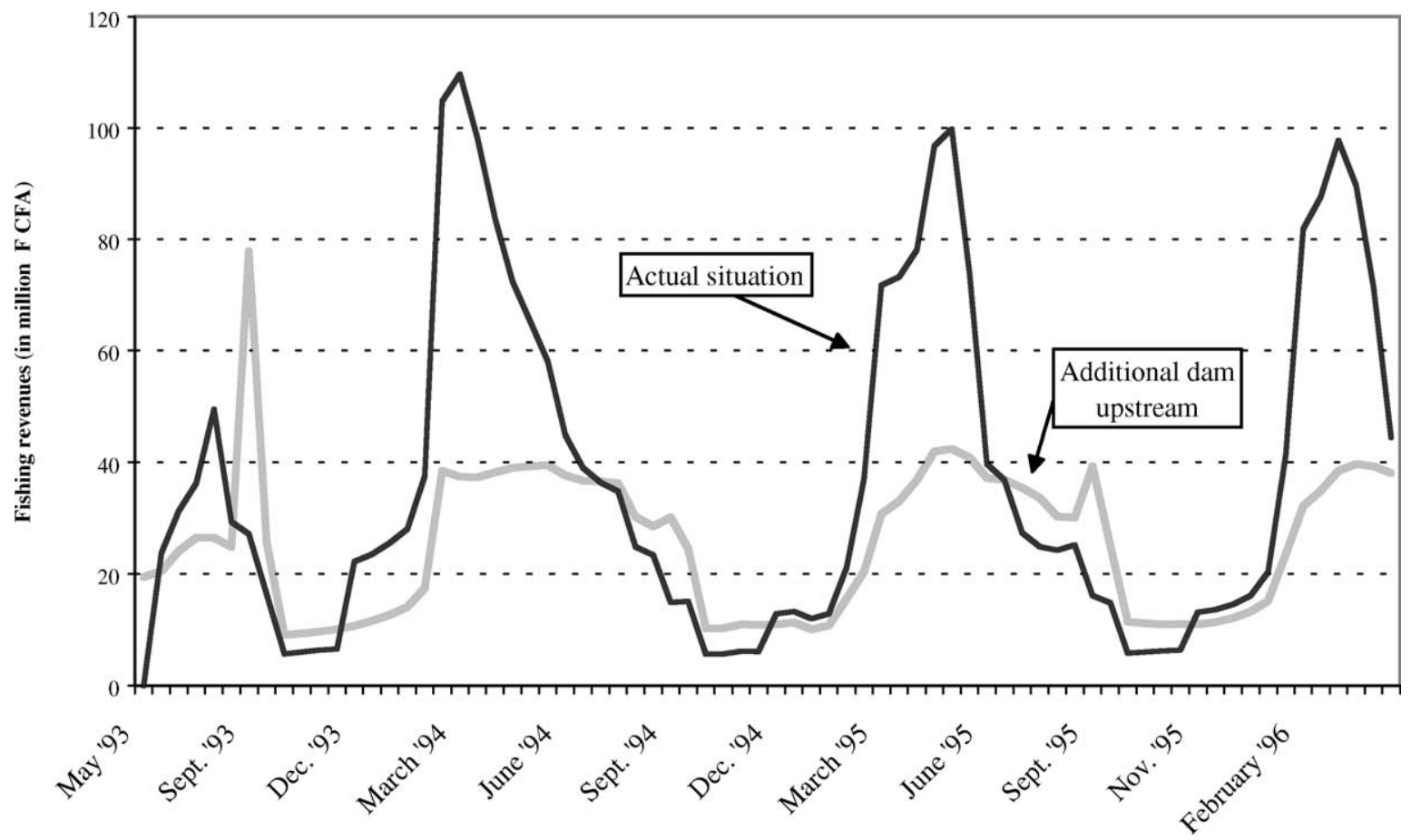

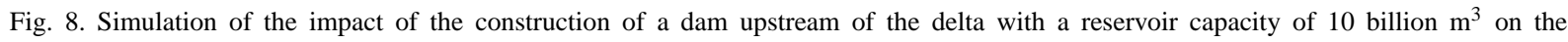
fishing revenues of farmers, compared to the actual situation, example of the Koli Koli River.

reservoir level of $260 \mathrm{~m}$, the impact of its back water curve was compared with the current situation for the flood plain of Goyroum (Fig. 9).

The impact of the dam on the water levels in the delta is important during the dry season and thus on the inundated area. The duration of the inundation is prolonged, modifying the ecosystem in the northern part of the delta. During a wet year (1994/1995), there is a negative impact on the rice cultivation, as there is too much water. However, during a dry year (e.g. 1993/1994) the impact on the rice cultivation is positive. There is a levelling impact on the fish catches during the year with a rather positive impact during a dry year. The impact of these river works during the flood season, is negligible.

\subsection{Impact of the flood levels: a sensitivity analysis}

A more detailed study of the impact of the different control parameters is possible by executing a sensitivity analysis, by which the value of a particular parameter is made to vary in ten steps. In Fig. 10, the simulation results of a sensitivity analysis of the catchability parameter are presented. This parameter varies between 40 and $400 \mathrm{~kg}$ per fishing trip in the model. This parameter increases when, for instance, the fishing equipment is modernised.

The impact of a variation of the catchability parameter on the fish catches and thus on the revenues of fishermen is clearly visible, especially during a dry year (1993/1994) when the catches are easier to obtain (less "dilution"). By taking rather extreme values for the catchability parameter, a plateau effect in the fish catches becomes visible (Bousquet et al., 1993). The extent of the fish stock is then the limiting factor for increasing the revenues. However, the impact of the catchability parameter on the fishing activities is nil, because this parameter does not intervene in the availability of fishermen and the allocation of fishermen to the different fishing zones. The fishermen continue to fish, even when their catches decrease.

In the current state of the model, a change in the value of one control parameter (e.g. the flood level parameter), does not modify the value of other control 


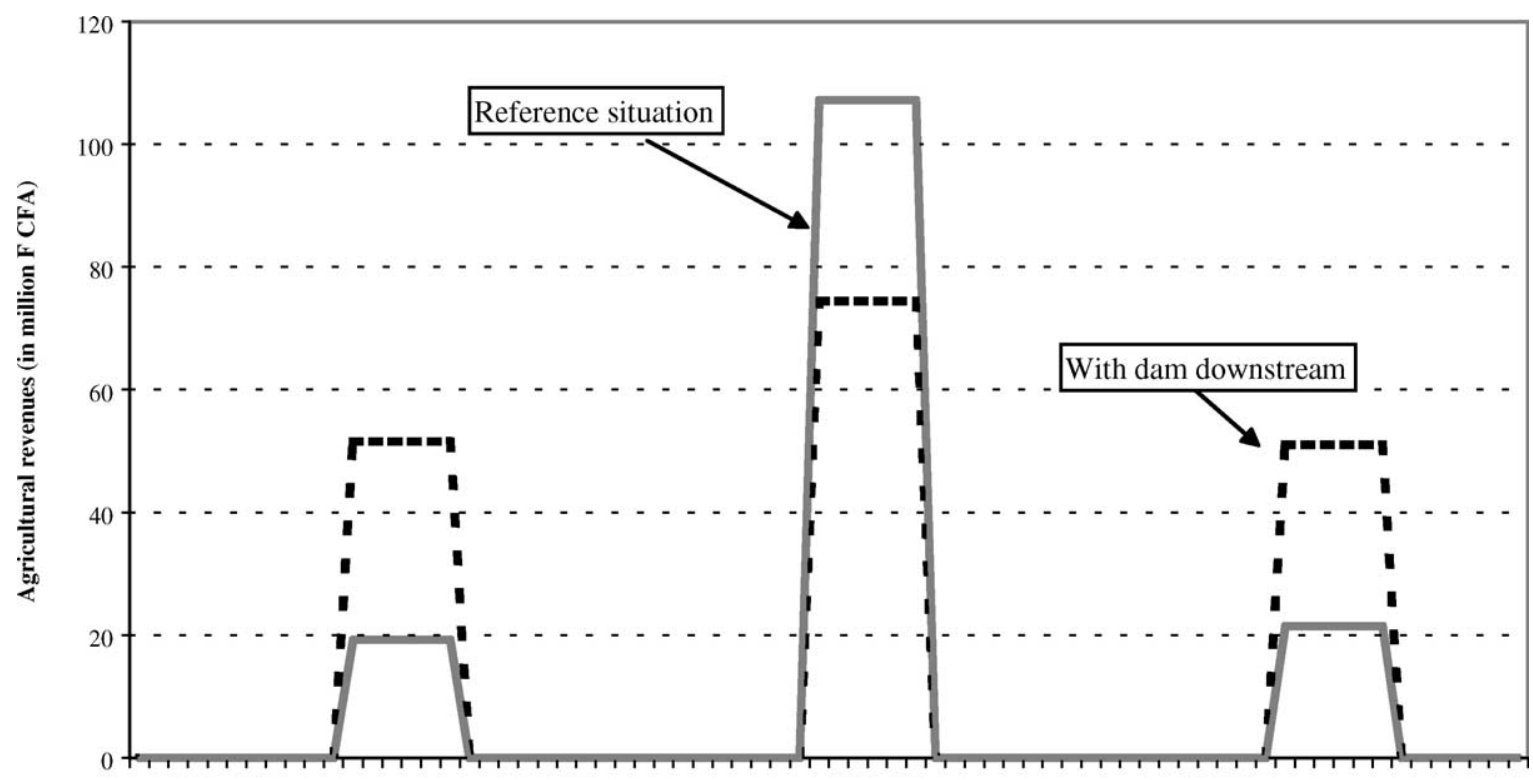

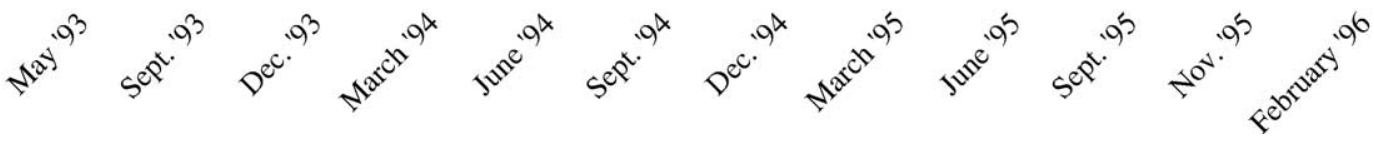

Fig. 9. Comparison of the simulation of the revenues of rice production in the Goyroum flood plain with and without the construction of the Tossaye dam, assuming a reservoir level of $260 \mathrm{~m}$.

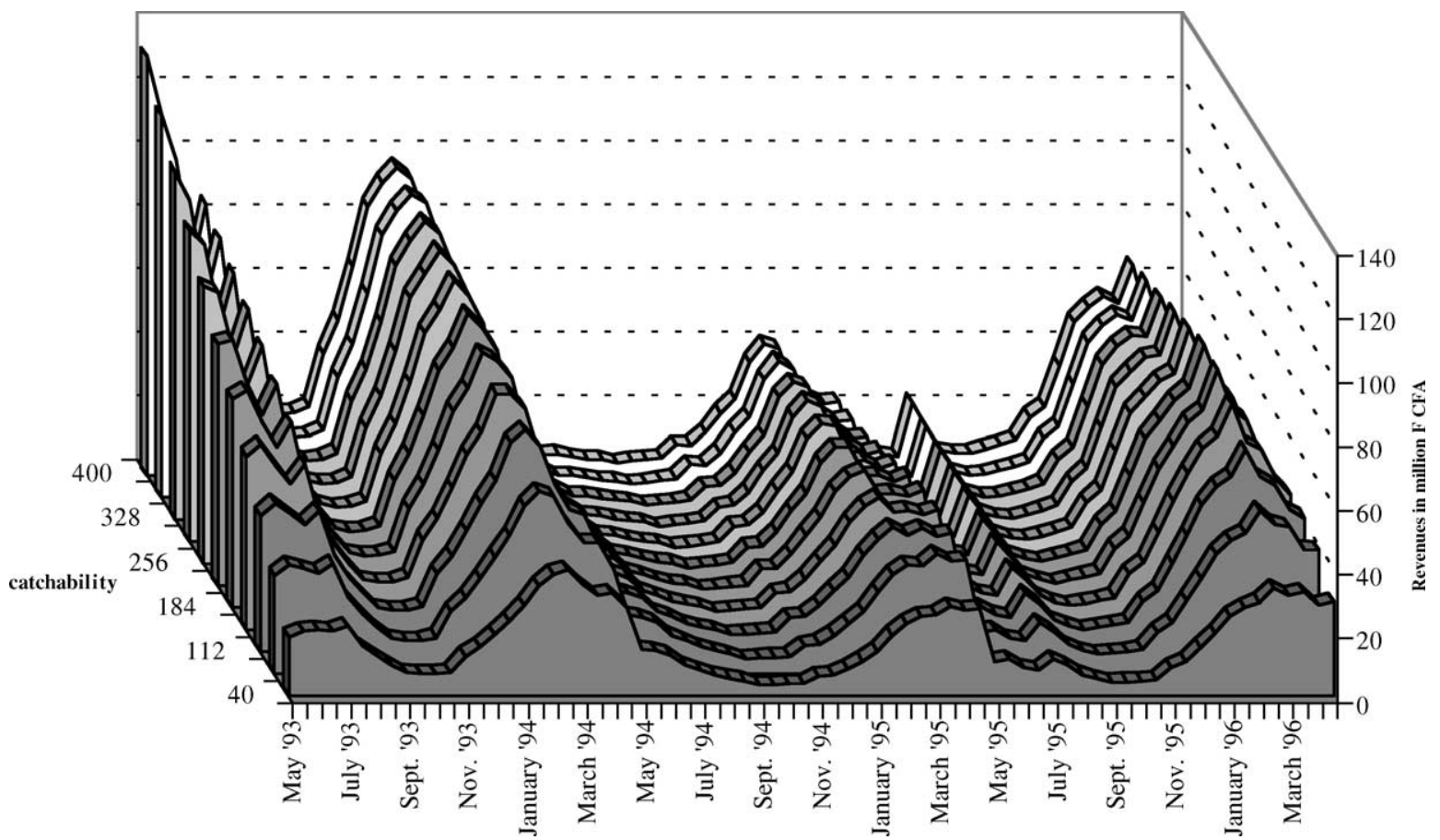

Fig. 10. Results of the simulation of a sensitivity analysis of the catchability on the fishing activities and revenues of the fishermen in the inner delta of the Niger river in Mali. 
parameters (e.g. the catchability parameter). A next step in the development of the model would include the study of the interdependence of the different mechanisms, and to formalise and model this transivity.

\section{Discussion}

\subsection{Integrated management and integrated modelling}

The concept of integrated management of natural resources is often evoked but not always clear in terms of content and method. The development and use of an integrated model representing the management of natural resources, combining physical and social processes is the occasion for clarifying this concept. In this study, rather than linking existing disciplinary models, an integrated model is developed. The integration consists in spatially representing the dynamics of the natural dynamics and social organisation of the ecosystem, thus combining different spatial and temporal organisational levels and scales as well as the knowledge of different scientific domains (bio-physical and social sciences). This differentiates the modelling approach presented here from the modelling exercises undertaken by most ecosystem modellers for a range of ecological systems (wetlands, shallow-water habitats, upland) who generally integrate physical and biological factors only (Fitz et al., 1996; Grant and Thompson, 1997). Fitz et al. (1996), who provide a useful overview of the different bio-physical models available in ecosystem research, specifically target a detailed representation of the various ecological processes involved (plant response to the nutrient status, for example). The modelling approach of this study is based on a unified spatial representation of the ecosystem inducing a considerable simplification and providing a better access for different actors to understanding the functioning of a complex system. This allows a change in paradigm in the field of ecosystem modelling. The results of the modelling exercise are not so much the scenarios that can be simulated by the model, but the fact that the model allows to understand the system as a whole and with such a spatial resolution that its interface (Fig. 4) permits a common platform for discussion for stakeholders of very different backgrounds (Robinson,
1991; Axelrod, 1997). This was the reason, for instance, to represent 3 specific hydrological years in the model instead of providing the possibility to the user to simulate the hydrology of the next 10 years to come. It was found that the model interface was accessible to a wide variety of actors, who discussed the integrated management of this ecosystem (Kuper et al., 2002). This confirms the statement of Grant and Thompson (1997) on the fact that elaborate quantitative models may be counterproductive in changing management practices.

The representation of spatial processes in the natural system of the malian delta (hydrology, aquatic biology) are based on the physical principle of diffusion, translated mainly in production and mixing equations. The representation of spatial processes that result from linking the natural system and the social system are based on economic principles. At each time step, a market equilibrium is reached that involves production areas, their carrying capacity - the markets-and production units, and their production costs, the agents. This equilibrium determines the migration of groups of producers.

This model indeed assumes:

- A discontinuous anisotropic representation of space instead of a continuous one.

- An intermediate level of granularity (a few hundreds of interacting units) specific to ecological systems instead of a low level of granularity (few interacting units) like in mathematical population models or a high one (thousands interacting units) like in individual based models.

- A behavioural model instead of a strategy model.

- A specific level of decision making: a decision of migration is made by a population of individuals and not by the individuals.

- An economic diffusion mechanism instead of a physical one.

The main goal of the integrated modelling was the exchange of information between scientists involved in the development of the model, which at times provoked a reorientation of disciplinary studies, and between the different stakeholders involved in the management of this ecosystem. By developing and testing scenarios, these actors assess the articulation (relationships, interactions, cause-effect, and evolution) between the different processes, which take 
place at different time steps and at different spatial scales. The driving forces governing these processes are thus identified, constituting potential policy and management interventions.

\subsection{A question of scale}

In terms of spatial analysis, it appears that a pertinent scale must be selected when coupling physical, ecological and social systems. This scale does not necessarily exist. In the case of the integrated model of the inner delta of Mali, it has been possible to determine such a pertinent scale due to specific modelling choices. By defining areas of this natural region as spatial entities, the complexity of the ecosystem could be captured and the meaning of each element within these entities understood. The connectivity of the system, which represents in fact hydrological connections, migration itineraries, fishing rights, herd routes, farming rights, constitutes an essential part of the spatial model. The integrated model has been structured around a spatial interface, allowing the understanding, the formalising and the dynamic representation of the mechanisms considered. This interface has provided a good means to reconstitute the complexity of the system while at the same time understanding the significance of each of the elements (objects, processes). The outputs were spatially defined, intended to promote the idea of considering this ecosystem as one management unit and not only as a mosaic of different administrative regions. Maps are often more tangible for the actors involved in the management of the ecosystem. This approach allows a further development and use of the model results by comparing model output with field observations.

\subsection{Validating the simulation results}

The classical concept of model validation, as understood in the bio-physical sciences, cannot be applied easily in the case of an integrated model representing a complex system with an interdependency of relationships and a mixture of bio-physical and human decisional processes (Konikow and Bredehoeft, 1992; Kuper, 1997; de Marsily, 1997). Robinson (1991) explains that the models used in the social sciences are not necessarily intended to make realistic predictions: “... in long-term forecasting, the models serve more to display the results of the assumptions embedded in the inputs or model structure than to reveal the likely future ...". The utility of these models is perhaps more clear when used for backcasting to show the requirements that need to be attained in order to reach a desired situation or goal (ibid). However, if the model results are to provide credible information to policy makers, managers, researchers, etc., the precision and the adequacy of the equations on which the model is based need to be verified (de Marsily, 1997). In addition, the limits of the use of the model in space, in time, need to be defined, while assuring that the processes on which the model is based have not been modified (ibid).

Three criteria are, therefore, proposed to justify the simulation results (Kuper, 1997; Strosser, 1997):

1. The plausibility of the model in terms of the spatial and temporal representation of the physical processes and the behaviour of the farmers. This plausibility has been tested in different sessions in Mali and in France with decision makers, technical staff of ministries and technical departments, researchers of the University of Bamako, farmers' representatives and NGOs. The criticism put forward by the different persons concerned the interface of the model, the sensitivity of certain control parameters, and the level of complexity of the mechanisms of the model. It never concerned the validity of the spatial representation (choice of objects and their attributes), the choice of the processes and mechanisms, and the time step (15 days).

2. The sensitivity analyses allow to isolate the impact of the different parameters on the fish catches, the rice production, and the livestock, and to determine the performance drivers of these farming systems (Gaunt et al., 1997). The identification of these parameters contributes to redefining the thematic sectoral research (investigation of constraining factors of the farming systems or potential adverse environmental impact) and offers the possibility to better formulate policy and management interventions.

3. The reproduction of a past event and the verification of the simulation results with system reality. By simulating the river flows before the installation of the Sélingué dam upstream of the delta, 
its impact on the different farming systems can be evaluated. The simulated river flows were verified by comparing simulated and actual water levels (Hassane et al., 2000). However, a comparison of the simulated and actual inundated areas through remote sensing remains to be undertaken (Mariko et al., 2003), while a comparison of simulated and actual fish catches, rice production and livestock demography should be undertaken with field data and thematic models (Laë, 1994; Olivry, 1995).

Axelrod (1997) adds two more criteria for verifying the validity of simulation models: research usability and extendibility. The first criterion relates to the transparency of the input and model structure in order to reconstitute its logic and hypotheses, and facilitate future use of (parts of) the model. The second criterion relates to the potential application of a given model to new uses. In our case, a modular approach was adopted during the development of the model, in order to facilitate the verification of the simulation results and avoid a black-box approach. A hydrologist, for instance, can verify the water levels and inundated areas for all hydrological entities. This modular approach fosters the transparency of the model structure (usability), clarifying at the same time the limits of the model (extendibility).

The different discussion sessions involving many actors of the system has allowed the research team to meet these criteria for the integrated model of the inner delta of the Niger River in Mali.

\section{Conclusion: on the applicability of the approach}

By representing the different farming systems (agriculture, fisheries, and livestock) the social organisation of the exploitation of the natural resources of the ecosystem has been captured. These farming systems are governed by traditional rules; the behaviour of the farming groups, with traditional rights on the natural resources (in time, in space) with typical mobility patterns was represented in the model by connecting these groups with specific farming zones for specific time periods. The availability of natural resources depends on the hydro-climatic conditions, while the farming production depends on different constraints and oppor- tunities of individual farming groups. Modifying different control parameters, for example the settlement pattern, can change this rather non-flexible representation. Obtaining a representation of the social organisation constitutes a challenge in the field of integrated modelling.

The efficiency of this approach should be related to the question whether the underlying principles can be generalised. This leads first to consider exploited ecosystems as a spatial complex of diffusive networks with a specific granularity (around 10 layers, around 100 entities per layer). This leads also to the use of economic diffusion processes instead of physical ones. The underlying hypothesis is that this permits to represent the relationship between the connectivity and the dynamics of a complex ecosystem.

\section{Acknowledgements}

The research of this paper was carried out in the context of the research programme Gihrex (Gestion Intégrée, Hydrologie, Ressources et Systèmes d'Exploitation of the Institut de Recherche pour le Développement) to which the following people contributed: R. Arfi, V. Bénech, M. Kuper, G. Mahé, B. Marieu, P. Morand, J.C. Olivry, D. Orange, Y. Poncet. We acknowledge the critical remarks of the participants of the February 2000 training, in Bamako. We thank the various organisations who provided us with data and advice: DNH (Direction Nationale de l'Hydraulique, Bamako), DRAMR (Direction Régionale de l'Appui au Monde Rural, Mopti, Timbuktu), IER (Institut d'Economie Rurale, Bamako), MDRE (Ministère du Développement Rural et de l'Eau, Bamako). Many thanks to J.M. Fritsch for useful comments on an earlier version of the paper.

\section{Appendix A. Croping of the flood by an upstream dam}

This scenario simulates the construction of a dam upstream of the delta on the Niger River basin, in addition to the existing Sélingué dam. By taking the evaporation of the reservoir of the dam into account, and maintaining the existing river diversions of the 
different irrigation systems, which amount to 3 billion $\mathrm{m}^{3}$ annually, it is hypothesised that this project will lead to a storage of water during the flood season (July-December) and water releases during the dry season (January-June). The rainfall-runoff relationship will be substantially modified, depending on the storage capacity of the projected dams, which varies from 5 to 15 billion $\mathrm{m}^{3}$ in the model. In the flood season the crest of the flood is flattened, while the natural discharge in the dry season is sustained. Since the annual inflow of the Niger river basin is about 30 billion $\mathrm{m}^{3}$, the maximum capacity proposed amounts to $50 \%$ of the inflow.

The impact of the storage capacity on the water levels in the delta was determined by analysing historical data sets (before the construction of the Sélingué dam) for a few key locations on the Niger river basin (Banankoro, Sélingué, Koulikoro, cf. Fig. 1) and in the delta (Ké-Macina, Tilembeya, Kara, Mopti, Aka, Awoye, Korientzé, Diré, Goundam), using stochastic relationships developed through multiple regression (Brunet-Moret et al., 1986; Marieu et al., 1998; Hassane et al., 2000). Similar relationships were established for other hydrological stations whenever these do not exist. Once these relationships were established, all hydrological entities were linked to these key points by interpolation. The impact on water levels was quantified using the following formula:

$h(t)=o(t)-f r(o(t)-a)$

where $h(t)$ is the water level at time step $t$ after commissioning of the dam, $o(t)$ the water level observed at time step $t$ in the actual situation (before commissioning of the new dam), $a$ the altitude of the bed level of the hydrological entity with reference to sea level (m), $f$ a control parameter, ranging from 0 to 1.2 , indicating the flood level with reference to the hydrological years 1993/1994, 1994/1995 and 1995/1996, and $r$ a control parameter, ranging from 0 to 1 , indicating the effect of the dam on the flood level.

The value for the reservoir index is 0.1 for a reservoir capacity of 5 billion $\mathrm{m}^{3}, 0.3$ for a capacity of 10 billion $\mathrm{m}^{3}$, and 0.4 for a capacity of 15 billion $\mathrm{m}^{3}$. In all cases, the flood level diminishes. These values are not uniform for all hydrological entities. Some entities are not affected (e.g. those situated on a tributary not influenced by the change in water level), others react differently (e.g. the lake complex
Télé-Faguibine, which is relatively far away from the main river course). The increase in water levels during the dry season varies between 0.35 and $0.5 \mathrm{~m}$ for a reservoir capacity of 5 billion $\mathrm{m}^{3}$, between 0.65 and $1.25 \mathrm{~m}$ for 10 billion $\mathrm{m}^{3}$ and between 0.8 and $2 \mathrm{~m}$ for 15 billion $\mathrm{m}^{3}$.

\section{Appendix B. Backwater effect due to dam downstream}

The scenario concerns the construction of a dam (Tossaye) $250 \mathrm{~km}$ downstream of the delta on the Niger River. HydroConsult (1996) has modelled the backwater effect of such a dam. Four levels of the water in the reservoir have been considered: $254,258.75$, 259.75 , and $260 \mathrm{~m}$. The $254 \mathrm{~m}$ level is the minimum water level in the proposed reservoir. According to the envisaged management rules (Coyne and Bellier, 1997), this level will have to be maintained throughout the dry season for environmental reasons. The levels of 258.75 and $259.75 \mathrm{~m}$ are the maximum water levels for two proposed dam options. The level of $260 \mathrm{~m}$ and higher would only be attained during high floods.

In this scenario, the monthly water levels at the barrage have been projected for a "dry year", i.e. 1993/1994, for three different scenarios: a maximum water level upstream of the dam of 258.75, 259.75, and $260 \mathrm{~m}$. The average annual discharge at Koulikoro in $1993 / 1994$ was $730 \mathrm{~m}^{3} / \mathrm{s}$, while it was $1390 \mathrm{~m}^{3} / \mathrm{s}$ for the period 1907-1998. The calculation of these monthly water levels is based on the hypothesis that the maximum water level of the dam is attained by the end of the flood season (beginning of March). The monthly water levels were calculated taking into account the natural inflow, the precipitation/evaporation and the minimum discharge to be furnished downstream, i.e. $75 \mathrm{~m}^{3} / \mathrm{s}$ according to the consultants.

The calculations of Hydroconsult show that the impact of the dam during the flood season is negligible, since the water levels are high and the back water curve coincides with the natural slope of the water immediately upstream of the reservoir. However, there is considerable impact during low water if the level of the reservoir is maintained higher than $254 \mathrm{~m}$. For a water level of $254 \mathrm{~m}$, there is no impact on the water levels in the delta: the back water curve joins the natural water levels at Bamba, $100 \mathrm{~km}$ upstream of 
the Tossaye dam. According to Hydroconsult, a water level of $258.75 \mathrm{~m}$ has a limited impact: the back water curve joins the natural water level just upstream of Koryoumé (port of Timbuktu). However, a water level of $259.75 \mathrm{~m}$ at the dam will have an impact up to Diré, $400 \mathrm{~km}$ upstream of Tossaye, and thus on the northern part of the delta, including the lakes Télé and Faguibine. A water level of $260 \mathrm{~m}$ and above (according to the consultants, the maximum water level is $261 \mathrm{~m}$ ) will have a significant impact upstream of Diré.

In the model, the impact of the back water curve of the Tossaye dam on the water levels in the delta is taken into account, by identifying the hydrological objects concerned for the different scenarios. The algorithms that we have used to modify the natural water levels are the following:

$w l(t)=\max ((a+w(t)-a) f, a+i)$

where $i$ is a control parameter that changes the water level at time $t$ for all hydrological entities concerned. The value of this parameter varies during the year and is not the same for all objects. Five groups are distinguished: the objects not concerned, those concerned at a water level of $254 \mathrm{~m}$ at the dam, and those concerned at water levels of $258.75,259.75$, and higher than $260 \mathrm{~m}$.

\section{References}

Axelrod, R., 1997. Advancing in the art of simulation in the social sciences. In: Conte, R., Hegselman, R., Terna, P. (Eds.), Simulating Social Phenomena. Springer, Berlin, pp. 21-40.

Baumann, E., Fay, C., Kassibo, B., 1994. Systèmes de production et d'activité: trois études régionales. In: Quensière, J. (Ed.), La pêche dans le Delta Central du Niger. ORSTOM-Karthala-IER, Paris, pp. 345-405.

Beverton, R.J.H., Holt, S.J., 1957. On the dynamics of exploited fish populations. Fish. Invest. London. II: 1-533.

Blöschl, G., Sivapalan, M., 1995. Scale issues in hydrological modeling: a review. J. Hydrol. Proc. 9 (3/4).

Bousquet, F., Morand, P., Quensière, J., Mullon, C., Pavé, A., 1993. Simulating the interaction between a society and a renewable resource. J. Biol. Syst. 1, 199-204.

Boyer, J.-F., Cochonneau, G., 1994. HYDROM 3.0: logiciel de gestion et d'exploitation de banque de données hydrométriques. In: Tankoano, J. (Ed.), Proceedings of the Second African Conference on Research in Computer Science, 12-18 October 1994, Ouagadougou, Burkina Faso, ORSTOM, Paris, pp. 235-237.

Breman, H., de Ridder, N., 1991. Manuel sur les pâturages des pays sahéliens. Karthala, Paris, 485 pp., maps.
Breuil, C., Quensière, J., 1995. Eléments d'une politique de développement durable des pêches et de la pisciculture au Mali. Food and Agriculture Organization of the United Nations, Rome, $35 \mathrm{pp}$.

Brunet-Moret, Y., Chaperon, P., Lamagat, J.P., Molinier, M., 1986. Monographie du Niger. Collection Monographies Hydrologiques no. 8, ORSTOM, Paris. vol. I-Niger supérieur, 396 pp., vol. II, Cuvette lacustre et Niger Moyen, 506 pp.

CIPEA-ODEM, 1983. Recherche d'une solution aux problèmes de l'élevage dans le delta intérieur du Niger au Mali. Ministère chargé du Développement rural, Addis-Abeba, Bamako, five volumes, vol. I, Les pâturages de la zone d'étude, 54 pp. + annexes, vol. II, Le cheptel de la zone d'étude, 193 pp., vol. III, Les leyde du delta intérieur du Niger, 390 pp., vol. IV, Les unités agro-pastorales, 236 pp., vol. V, Rapport de synthèse, $151 \mathrm{pp}$.

Coyne et Bellier consultants, 1997. Rapport de factibilité du scénario de développement de la boucle du Niger. Paris, France, Three volumes, vol. I, Rapport de synthèse, 150 pp., vol. II, Rapport principal, 210 pp. + annexes, vol. III, Plans, 19 maps.

Fitz, H.C., DeBellevue, E.B., Costanza, R., Boumans, R., Maxwell, T., Wainger, L., Sklar, F.H., 1996. Development of a general ecosystem model for a range of scales and ecosystems. Ecol. Modell. 88, 263-295.

Gallais, J., 1967. Le delta intérieur du Niger, études de géographie régionale. IFAN-Larose, Dakar-Paris. Two volumes, $621 \mathrm{pp}$.

Gaunt, J.L., Riley, J., Stein, A., Penning de Vries, F.W.T., 1997. Requirements for effective modelling strategies. Agric. Syst. 54, 153-168.

Gleick, P.H., 2000. The changing water paradigm a look at twenty-first century water resources development. Water Int. $25,127-138$.

Grant, W.E., Thompson, P.B., 1997. Integrated ecological models: simulation of socio-cultural constraints on ecological dynamics. Ecol. Modell. 100, 43-59.

Hassane, A., Kuper, M., Orange, D., 2000. Influence des aménagements hydrauliques et hydro-agricoles du Niger supérieur sur l'onde de la crue du delta intérieur du Niger au Mali. Sud Sciences et Technologies 5, 16-31.

HydroConsult, 1996. Etude de factibilité et d'impact du barrage de Tossaye. G.I.E. ORSTOM-EDF, Paris. Two volumes.

Konikow, L.F., Bredehoeft, J.D., 1992. Groundwater models cannot be validated. Adv. Water Resources Res. 15, 75-83.

Kuper, M., 1997. Irrigation management strategies for improved salinity and sodicity control. Ph.D. thesis, Agricultural University of Wageningen, The Netherlands. $238 \mathrm{pp}$.

Kuper, M., Mullon, C., Poncet, Y., Morand, P., Orange, D., Arfi, R., Mahé, G., Benga, E., 2002. La modélisation intégrée d'un écosystème inondable: le cas du delta intérieur du Niger. In: Orange, D., Arfi, R., Kuper, M., Morand, P., Poncet, Y. (Eds.), Proceedings of the international seminar on Gestion intégree des ressources naturelles en zones inondables tropicales. IRD, Paris, pp. 773-798.

Laë, R., 1994. Modification des apports en eau et impact sur les captures de poisson. In: Quensière, J. (Ed.), La pêche dans le Delta Central du Niger, ORSTOM-Karthala-IER, Paris, pp. 255-265. 
Laë, R., Morand, P., 1994. Typologie des cycles d'activité halieutique: ménages sédentaires et petits migrants du secteur de Mopti. In: Quensière, J. (Ed.), La pêche dans le Delta Central du Niger, ORSTOM-Karthala-IER, Paris, pp. 287-294.

Lee, D.J., Dinar, A., 1995. Review of integrated approaches to river basin planning, development and management, World Bank Policy Research Working Paper no. 1446, Washington D.C., $18 \mathrm{pp}$.

Mariko, A., Mahé, G., Orange, D., Royer, A., Nonguierma, A., Amani, A., Servat, E., 2003. Suivi des zones d'inondation du delta intérieur du Niger: perspectives avec les données de basse résolution NOAA/AVHRR. In: Orange, D., Arfi, R., Kuper, M., Morand, P., Poncet, Y. (Eds.), Proceedings of the international seminar on Gestion intégrée des ressources naturelles en zones inondables tropicales. IRD, Paris, pp. 231-244.

de Marsily, G., 1997. De la validation des modèles en sciences de l'environnement. In: Blasco, F. (Ed.), Tendances nouvelles en modélisation pour l'environnement. Elsevier, Paris, pp. $375-382$.

Marieu, B., Bamba, F., Briquet, J., Cissé, N., Gréard, M., Henry des Tureaux, T., Mahé, G., Mahieux, A., Olivry, J.-C., Orange, D., Picouet, C., Sidibé, M., Touré, M., 1998. Actualisation des données hydrométriques du fleuve Niger au Mali pour EQUANIS. ORSTOM-DNHE, Bamako, Mali, 82 pp.

McIntire, J., 1981. Rice consumption in West Africa. In: Pearson, S.R., Stryker, J.D., Humphreys, P. (Eds.), Rice in West Africa: Policy and Economics. Stanford University Press, 482 pp.
Olivry J.C., 1995. Fonctionnement hydrologique de la cuvette lacustre du Niger et essai de modélisation de l'inondation du delta intérieur. In: Olivry, J.C., Boulègue, J. (Eds.), Grands bassins fluviaux périatlantiques: Congo, Niger, Amazone. ORSTOM, Paris, pp. 267-280.

Poncet, Y., Orange, D., 1999. L'eau, moteur de ressources partagées: l'exemple du delta intérieur du Niger au Mali. Aménagement et Nature 132, 97-108.

Poncet, Y., Kuper, M., Mullon, C., Morand, P. Orange, D., 2001. Représenter l'espace pour structurer le temps: La modélisation intégrée du delta intérieur du Niger au Mali. In: Lardon, S., Maurel, P., Piveteau, V. (Eds.), Représentations spatiales et développement territorial, Hermès, Paris, pp. 143-162.

Quensière, J. (Ed.), 1994. La pêche dans le delta central du Niger. IER-Orstom-Karthala, Paris. 495 pp., maps.

Robinson, J.B., 1991. Modelling the interactions between human and natural systems. Int. Soc. Sci. J. 130, 629-647.

Schulz, G.A., 2000. Potential of modern data types for future water resources management. Water Int. 25, 96-105.

Simonovic, S.P., 2000. Tools for water management one view of the future. Water Int. 25, 76-88.

Strosser, P., 1997. Analyzing alternative policy instruments for the irrigation sector. Ph.D. thesis, Agricultural University of Wageningen, The Netherlands. 243 pp.

Viguier P., 1937. Riziculture indigène au Soudan français. Three volumes, 326 pp., 71 pp., 154 pp. 